\title{
Thrombocytopenia in patients with aortopulmonary transposition and an intact ventricular septum
}

\author{
MASARU TERAI, MAKOTO NAKAZAWA, ATSUYOSHI TAKAO, \\ YASUHARU IMAI \\ From the Departments of Paediatric Cardiology and Paediatric Cardiovascular Surgery, The Heart Institute \\ of Japan, Tokyo Women's Medical College, Tokyo, Japan
}

SUMMARY Relations between platelet counts and mean pulmonary arterial pressures, capillary oxygen tension, and haematocrit were studied in 37 patients, aged 2 to 16 months, with simple aortopulmonary transposition (an intact ventricular septum and no ductus arteriosus). There was a statistically significant inverse relation between pulmonary arterial pressures and platelet counts. Six out of the eight patients (4-16 months old) with raised mean pulmonary arterial pressure had thrombocytopenia $\left(<100000 / \mathrm{mm}^{3}\right)$ and none of the 25 patients with a normal mean pulmonary pressure ( $\leqslant 20 \mathrm{~mm} \mathrm{Hg}$ ) showed thrombocytopenia. Pulmonary arterial pressures were not measured in four patients: the platelet count was $7000 / \mathrm{mm}^{3}$ in the patient with a left ventricular systolic pressure of $90 \mathrm{~mm} \mathrm{Hg}$ but it was $>100000 / \mathrm{mm}^{3}$ in the three in whom left ventricular systolic pressure was $<50 \mathrm{~mm} \mathrm{Hg}$. Platelet counts were positively correlated with capillary oxygen tension and inversely correlated with haematocrit in all 37 patients. Despite the persistence of pulmonary hypertension, thrombocytopenia improved after corrective surgery in five patients, even in those who had thrombocytopenia before operation.

These data suggest that the presence of thrombocytopenia is not solely related to the development of pulmonary vascular disease. Pulmonary vascular disease, however, does contribute to the early development of thrombocytopenia in patients with simple aortopulmonary transposition.

Haematological abnormalities including polycythaemia, thrombocytopenia, and hypercoaguability are often reported in patients with cyanotic heart disease. ${ }^{1-3}$ These abnormalities can cause serious perioperative complications. Although some studies have indicated that patients with cyanotic heart disease may have disseminated intravascular coagulation ${ }^{4-6}$ others have not. ${ }^{27}$

We have found severe thrombocytopenia with a bleeding tendency in some of our patients with simple aortopulmonary transposition (an intact ventricular septum and no ductus arteriosus) in whom pulmonary arterial pressure is raised. This prompted an investigation of the association of thrombocytopenia and pulmonary hypertension in patients with simple aortopulmonary transposition.

Requests for reprints to Dr Makoto Nakazawa, Department of Paediatric Cardiology, The Heart Institute of Japan, Tokyo Women's Medical College, 10 Kawada-cho, Shinjuku, Tokyo. 162, Japan.

Accepted for publication 9 December 1986

\section{Patients and methods}

We studied 37 consecutive patients (aged 2-16 months (mean 8)) with simple aortopulmonary transposition who underwent preoperative cardiac catheterisation at our hospital between January 1979 and March 1985. Patients with a ductus arteriosus were excluded from the study.

Pulmonary arterial pressure was measured in 33 patients, and in these patients we studied the interrelation between platelet counts and mean pulmonary arterial pressures. We also studied the relations between platelet counts and the capillary oxygen tension or haematocrit value in 37 patients, including the four patients in whom pulmonary arterial pressures were not measured. The platelet count was obtained with a Coulter Thrombocounter at the time of preoperative haemodynamic assessment. When thrombocytopenia was found we used the Rees-Ecker method to confirm the count. A 


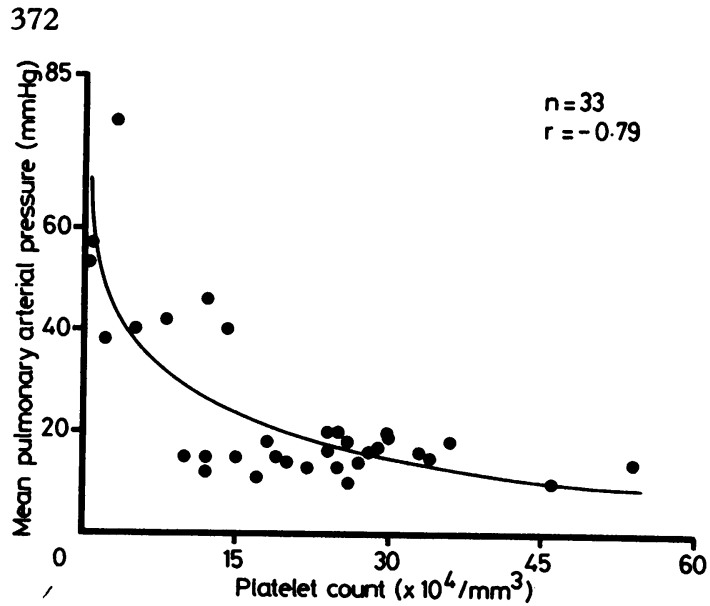

Fig 1 Inverse correlation between platelet counts and mean pulmonary arterial pressure. This relation is non-linear; the best fit is obtained with the logarithmic function $(r=-0.79, p<0.001)$.

platelet count of $<100000 / \mathrm{mm}^{3}$ was regarded as showing thrombocytopenia.

Correlations between the platelet count and the mean pulmonary arterial pressure, capillary oxygen tension, and haematocrit were tested by regression analysis with simple linear or logarithmic equations.

\section{Results}

RELATIONS BETWEEN PLATELET COUNTS AND MEAN PULMONARY ARTERIAL PRESSURES, CAPILLARY OXYGEN TENSION, AND

HAEMATOCRIT

In the 33 patients in whom pulmonary arterial pressures were known, platelet counts were inversely correlated with mean pulmonary arterial pressures (mean pulmonary arterial pressure $=57-12.3 \log _{\mathrm{e}}$ (platelet counts $/ 10^{4}$ ); $\mathrm{r}=-0.79, \mathrm{p}<0.001$ (fig 1)). For example, six of the eight patients with raised mean pulmonary arterial pressure had thrombocytopenia $\left(<100000 / \mathrm{mm}^{3}\right)$. The other two patients with a raised pulmonary pressure had platelet counts of $120000 / \mathrm{mm}^{3}$ and $140000 / \mathrm{mm}^{3}$. None of the 25 patients with a normal mean pulmonary arterial

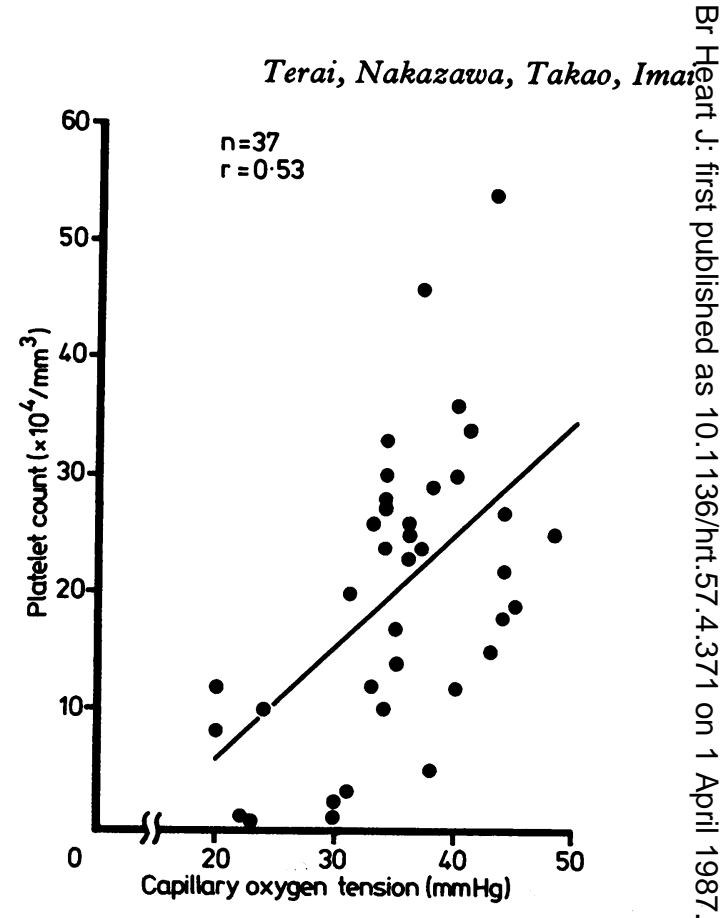

Fig 2 Relation between platelet counts and capillary oxygen tension $(r=0.53, p<0.01)$.

pressure ( $\leqslant 20 \mathrm{~mm} \mathrm{Hg}$ ) was thrombocytopenic.

In the four patients in whom pulmonary arterial $\stackrel{\circ}{\Phi}$ pressures were not measured the platelet count was $7000 / \mathrm{mm}^{3}$ in a patient (case 7 in table) with a left $\frac{0}{3}$ ventricular systolic pressure of $90 \mathrm{~mm} \mathrm{Hg}$ and $>100000 / \mathrm{mm}^{3}$ in the three patients in whom left ventricular systolic pressure was $<50 \mathrm{~mm} \mathrm{Hg}$.

Platelet counts were also related to capillary oxygen tension $(r=0.53, p<0.01)$ and inversely to the haematocrit $(r=-0.71, p<0.01)$ in all 37 patients (figs 2 and 3 ).

\section{CLINICAL CHARACTERISTICS IN PATIENTS WITH THROMBOCYTOPENIA}

Seven $(19 \%)$ of the 37 patients were thrombo- $D$ cytopenic. The table summarises the clinical features. Their ages at catheterisation ranged from four $\tilde{\sigma}$

Table Characteristics of thrombocytopenic patients

\begin{tabular}{|c|c|c|c|c|c|c|c|c|}
\hline \multirow[b]{2}{*}{$\begin{array}{l}\text { Case } \\
\text { No }\end{array}$} & \multirow[b]{2}{*}{$\begin{array}{l}\text { Age } \\
\text { (mnth) }\end{array}$} & \multicolumn{4}{|l|}{ Before surgery } & \multirow[b]{2}{*}{ Surgery } & \multicolumn{2}{|l|}{ After surgery } \\
\hline & & $\begin{array}{l}\text { Platelets } \\
\left(\times 10^{4} / \mathrm{mm}^{3}\right)\end{array}$ & $\begin{array}{l}\mathrm{Po}_{2} \\
(\mathrm{~mm} \mathrm{Hg})\end{array}$ & $\begin{array}{l}\text { Haematocrit } \\
(\%)\end{array}$ & $\begin{array}{l}M P A P \\
(m m H g)\end{array}$ & & $\begin{array}{l}\text { Platelets } \\
\left(\times 10^{4} / \mathrm{mm}^{3}\right)\end{array}$ & $\begin{array}{l}M P A P \\
(m m H g)\end{array}$ \\
\hline $\begin{array}{l}1 \\
2 \\
3 \\
4 \\
5 \\
6 \\
7\end{array}$ & $\begin{array}{r}11 \\
16 \\
4 \\
12 \\
12 \\
15 \\
12\end{array}$ & $\begin{array}{l}2 \\
1 \\
8 \\
0 \cdot 6 \\
3 \\
5 \\
0 \cdot 7\end{array}$ & $\begin{array}{l}30 \\
22 \\
20 \\
23 \\
31 \\
38 \\
30\end{array}$ & $\begin{array}{l}60 \\
62 \\
63 \\
65 \\
61 \\
73 \\
66\end{array}$ & $\begin{array}{l}38 \\
57 \\
42 \\
53 \\
81 \\
40 \\
\text { ND }\end{array}$ & $\begin{array}{l}\text { Senning } \\
\text { Senning } \\
\text { PAB, BT } \\
\text { Senning } \\
\text { Senning } \\
\text { Jatene } \\
\text { Jatene }\end{array}$ & $\begin{array}{r}22 \\
21 \\
1 \\
23 \\
39 \\
19 \\
4\end{array}$ & $\begin{array}{l}78 \\
\text { ND } \\
67 \\
\text { ND } \\
67 \\
29 \\
83\end{array}$ \\
\hline
\end{tabular}

Po, capillary oxygen tehsion; MPAP, mean pulmonary artery pressure; PAB, pulmonary artery banding; BT, Blalock-Taussig shunt; $\mathrm{ND}$, not done. 


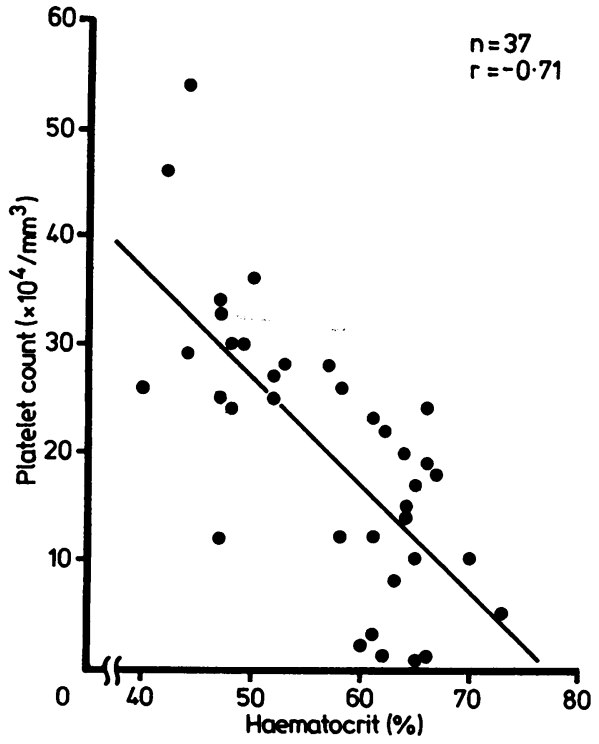

Fig 3 Inverse relation between platelet counts and haematocrit $(r=-0.71, p<0.01)$.

to 16 months and five of them were between 12 and 16 months old.

Five patients who had a platelet count of $<30000 / \mathrm{mm}^{3}$ showed haemorrhagic complications such as generalised petechiae or purpura and haematuria. Bone marrow aspiration in three patients showed adequate numbers of megakaryocytes with normal platelet production in all of them.

Six patients (cases 1-6) had raised mean pulmonary arterial pressures $(38-81 \mathrm{~mm} \mathrm{Hg}$ ) before operation. The thrombocytopenic $\left(7000 / \mathrm{mm}^{3}\right)$ patient (case 7) in whom the pulmonary arterial pressure was not measured had a left ventricular systolic pressure of $90 \mathrm{~mm} \mathrm{Hg}$. In this case no pulmonary stenosis was found at operation.

After catheterisation all seven patients underwent operation: a Senning operation in four, a Jatene procedure with a Lecompte modification in two, and pulmonary arterial banding with Blalock-Taussig shunt in one. Pulmonary arterial pressure was measured in five of them one day to four years after operation. Mean pulmonary arterial pressure had not fallen to normal ( $\leqslant 20 \mathrm{~mm} \mathrm{Hg}$ ) in any of them. One patient (case 7) died of pulmonary vascular obstruction eight days after operation.

In all six survivors the postoperative platelet count increased to normal within $\mathbf{3 0}$ days after operation. In one patient (case 3) who had undergone palliative surgery, however, hypoxaemia developed five months after operation; thrombocytopenia progressed when the mean pulmonary arterial pressure reached $67 \mathrm{~mm} \mathrm{Hg}$.

\section{Discussion}

Thrombocytopenia develops gradually in patients with cyanotic heart disease. ${ }^{7-9}$ Ekert et al reported platelet counts of $<100000 / \mathrm{mm}^{3}$ in eight of 28 patients with cyanotic heart diseases, including aortopulmonary transposition; all eight were more than three years old. ${ }^{7}$ Paul et al showed that thrombocytopenia was rare in infants aged less than a year. ${ }^{9}$ Gross et al showed that thrombocytopenia was most common in older patients with hypoxaemia and polycythaemia. ${ }^{8}$ Thus it seems likely that the severity of thrombocytopenia in patients with cyanotic heart disease is related to the duration of both hypoxaemia and polycythaemia. The present study also showed that the severity of hypoxaemia and polycythaemia was significantly related to the platelet count. Some investigators have demonstrated a decrease in platelet life span in cyanotic patients with normal platelet counts as well as in those with thrombocytopenia, ${ }^{1011}$ suggesting that there may be compensated thrombocytolysis with relative and absolute megathrombocytosis in cyanotic patients.

In our patients with simple aortopulmonary transposition thrombocytopenia was even found in patients aged less than 18 months if pulmonary arterial pressure was increased. In addition, continuing high pulmonary arterial pressures in these patients after corrective surgery indicated the presence of pulmonary vascular obstructive disease. The early occurrence of thrombocytopenia associated with advanced pulmonary vascular disease may be a specific feature of simple aortopulmonary transposition.

It is now generally thought that pulmonary vasoconstriction caused by hypoxaemia, a high haematocrit, and increased pulmonary blood flow may increase the shear stress on the endothelium and cause endothelial damage. Platelets aggregate at such sites. All three factors occur in simple aortopulmonary transposition and this may explain the rapid progression of pulmonary vascular disease in such patients. ${ }^{12}$ Wagenvoort et al in their histological study of patients with simple aortopulmonary transposition showed that the pulmonary arteries had thin walls and wide lumens, especially in patients with high haematocrits. ${ }^{13}$ Moreover, they found intimal fibrosis indicative of organised thrombi in some of their patients. Pulmonary thrombi contribute to further progressive vascular disease. ${ }^{14} \mathrm{An}$ association of pulmonary vascular disease and thrombocytopenia has not been established, however.

As we have shown, corrective surgery resulting in increased oxygen saturation can increase platelet 
counts in patients with severe thrombocytopenia before operation, despite the persistence of pulmonary hypertension. Clearly the presence of thrombocytopenia is not solely related to the development of pulmonary vascular disease. The pulmonary vascular state may, however, influence the rate of destruction of platelets in the lung. In other words the association of pulmonary vascular disease may contribute to the early induction of thrombocytopenia in patients with simple aortopulmonary transposition.

Although the basic mechanism has not been confirmed, thrombocytopenia is an important clinical finding which indicates the presence or development of pulmonary vascular disease. Operation during early infancy should prevent the development of pulmonary vascular disease and haematological abnormalities.

\section{References}

1 Iolster NJ. Blood coagulation in children with cyanotic congenital heart disease. Acta Paediatr Scand 1970;59:551-7.

2 Wedemeyer AL, Edson JR, Krivit W. Coagulation in cyanotic congenital heart disease. Am J Dis Child 1972;124:656-60.

3 Wedemeyer AL, Lewis JH. Platelet survival studies in cyanotic cardiac patients [Abstract]. J Pediatr 1973;83:161.

4 Dennis LH, Stewart JL, Conrad ME. Heparin treat- ment of haemorrhagic diathesis in cyanotic con $\frac{7}{2}$ genital heart disease. Lancet 1967;i:1088-9.

5 Komp DM, Sparrow AW. Polycythemia in cyanoti示 heart disease-a study of altered coagulation. Pediatr 1970;76:231-6.

6 Ihenacho HNC, Breeze GR, Fletcher DJ, Stuart Consumption coagulopathy in congenital heart disease. Lancet 1973;i:231-4.

7 Ekert H, Gilchrist GS, Stanton R, Hammond Do Hemostasis in cyanotic congenital heart disease. $L$ Pediatr 1970;76:221-30.

8 Gross S, Keefer V, Liebman J. The platelets in cy= anotic congenital heart disease. Pediatrics $1968 \mathrm{~W}$ 42:651-8.

9 Paul MH, Currimbhoy Z, Miller RA, Schulman Thrombocytopenia in cyanotic congenital heart dis $-\mathrm{V}$ ease [Abstract]. Circulation 1961;24:1013.

10 Waldman JD, Czapek EE, Paul MH, Schwartz AD w Levin DL, Schindler S. Shortened platelet survivat in cyanotic heart disease. J Pediatr 1975;87:77-9. 은

11 Goldschmidt B, Sarkadi B, Gardos G, Matlary A. Platelet production and survival in cyanotic con genital heart disease. Scand J Haematol 1974 13:110-5.

12 Aziz KU, Paul MH, Rowe RD. Bronchopulmonare circulation in d-transposition of the great arteries. Possible role in genesis of accelerated pulmonary vas cular disease. Am J Cardiol 1977;39:432-8.

13 Wagenvoort CA, Nauta J, van der Schaar PJ, Weed HWH, Wagenvoort $\mathrm{N}$. The pulmonary vasculature in complete transposition of the great vessels, judge from lung biopsies. Circulation 1968;38:746-54.

14 Newfeld EA, Paul MH, Muster AJ, Idriss FS. Pu $\vec{E}$ monary vascular disease in transposition of the greab vessels and intact ventricular septum. Circulation 1979;59:525-30. 